\title{
Penerapan Metode Forward Chaining Dalam Sistem Pakar Pendeteksi Kerusakan Air Conditioner (AC) Berbasis Android
}

\author{
Aprih Widayanto ${ }^{1}$, Febrian Aji Pratama ${ }^{2}$ \\ ${ }^{1}$ STMIK Nusa Mandiri \\ ${ }^{2}$ Universitas Bina Sarana Informatika \\ 1'aprih.apz@nusamandiri.ac.id, ${ }^{2}$ febrianaji81@gmail.com
}

\begin{abstract}
The progress of computer technology has helped many people in various fields of life. Expert systems are computer programs with expert knowledge to solve certain problems such as imitating human thought. Air Conditioner $(A C)$ is a machine made to stabilize the humidity of an area and the temperature of the air. The lack of knowledge of the owner of the $A C$ equipment has resulted in the equipment being damaged and the technical maintenance of the $A C$, and the amount of costs incurred for maintenance services is one of the obstacles. Based on these problems, the author made an expert system application to detect damage to Android-based air conditioners. . This application is expected to help the community in detecting damage, causes and solutions in Air Conditioning (AC). Interview and literature studies are data collection techniques used by the authors. In making the program the author uses the Forward Forward Chaining method. In this application there are 4 main menus, namely diagnosis, info, about and exit.
\end{abstract}

Keywords: Expert System, Air Conditioner (AC), Forward Chaining, Android

Abstrak: Kemajuan teknologi komputer banyak membantu manusia dalam berbagai bidang kehidupan. Sistem pakar merupakan program komputer yang meniru pengetahuan dan pemikiran pakar untuk menyelesaikan suatu masalah yang spesifik. Air Conditioner (AC) adalah mesin yang dirancang untuk menstabilkan kelembaban suatu area dan suhu udara. Kurangnya pengetahuan pemilik terhadap peralatan AC yang dimilikinya mengakibatkan peralatan menjadi rusak dan teknis perawatan $\mathrm{AC}$, serta besarnya biaya yang dikeluarkan atas jasa perawatan menjadi salah satu kendala. Berdasarkan permasalahan tersebut, penulis membuat aplikasi sistem pakar untuk mendeteksi kerusakan AC berbasis android. . Aplikasi ini diharapkan dapat membantu masyarakat dalam mendeteksi kerusakan, penyebab dan solusi pada Air Conditioner (AC). Teknik pengumpulan data yang digunakan penulis adalah wawancara dan studi pustaka. Dalam membuat program penulis menggunakan merode Forward Chaining. Pada aplikasi ini terdapat 4 menu utama yaitu diagnosa, info, tentang dan keluar.

Kata Kunci : Sistem Pakar, Air Conditioner (AC), Forward Chaining, Android

(7) This is an open access article distributed under the Creative Commons Attribution License, which permits unrestricted use, distribution, and reproduction in any medium, provided the original work is properly cited. (02019 by author and IJSE-Indonesian Journal on Software Engineering.

\section{A. PENDAHULUAN}

Kemajuan teknologi komputer banyak membantu manusia dalam berbagai bidang kehidupan. Sistem pakar adalah program komputer yang di desain untuk meniru kemampuan memecahkan masalah dari seorang pakar [Resmiati and Supriatna, 2016]. Dengan sistem pakar, pengetahuan yanghanya dapat diperoleh oleh para ahli di bidangnya dapat diselesaikan oleh orang awam walaupun hanya sekedar mencari informasi atau menangani permasalahan. Air Conditioner (AC) adalah mesin yang dirancang untuk menstabilkan suhu udara dan kelembaban suatu area. AC adalah salah satu alat elektronik yang paling banyak digunakan 
masyarakat untuk menyejukan ruangan, sehingga membantu mereka memperoleh kenyamanan dalam menjalankan kegiatan sehari-hari di dalam ruangan.

Peralatannya banyak dipasang di mana saja sesuai dengan kebutuhan dari penggunanya, mulai dari rumah pribadi, rumah sakit, sekolah, gedung perkantoran. Perawatan secara berkala diperlukan agar selalu dalam kondisi yang optimal. Pemakaian yang terus menerus sehingga mengakibatkan peralatan mengalami banyak masalah. Kurangnya pengetahuan pemilik terhadap peralatan AC yang dimilikinya mengakibatkan peralatan menjadi rusak dan tidak bisa dipakai sama sekali. Ketersediaan sumber daya pakar dalam teknis perawatan AC, serta besarnya biaya yang dikeluarkan atas jasa perawatan menjadi salah satu kendala.

\section{B. TINJAUAN PUSTAKA}

\section{Program}

Menurut Sutarman dalam [Vadlya Maarif, Andrian Eko Widodo, 2017] mengatakan "Program adalah barisan perintah atau instruksi yang disusun sehingga dapat dipahami oleh komputer dan kemudian dijalankan sebagai barisan perhitungan numerik, di mana barisan perintah tersebut berhingga, berakhir, dan menghasilkan output".

\section{Sistem Pakar}

Menurut John Durkin dalam [Resmiati and Supriatna, 2016] mengemukakan "Sistem Pakar (Expert System) adalah aplikasi berbasis komputer yang digunakan untuk menyelesaikan masalah sebagaimana yang dipikirkan oleh pakar".

Menurut Arhami dalam [Vadlya Maarif, Andrian Eko Widodo, 2017] mengatakan "Sistem pakar adalah salah satu cabang dari kecerdasan buatan yang membuat penggunaan secara luas pengetahuan yang khusus untuk penyelesaian masalah tingkat manusia yang pakar".

Menurut Kusrini dalam [Ma'rifati and Kesuma, 2018] mengatakan Sistem pakar (expert system) adalah "Sistem berbasis komputer yang menggunakan pengetahuan, fakta dan teknik penalaran yang biasanya hanya dapat dipecahkan oleh seorang pakar dalam bidang tersebut". Sistem Pakar memberikan nilai tambah pada teknologi untuk membantu dalam menangani era informasi yang canggih.

\section{Mesin Inferensi Forward Chaining}

Mesin Inferensi adalah bagian yang mengandung fungsi berpikir dan pola-pola penalaran sistem yang digunakan oleh seorang pakar. Mekanisme ini akan menganalisa suatu masalah tertentu dan selanjutnya akan mencari jawaban atau kesimpulan terbaik. [Yuwono et al., 2017].

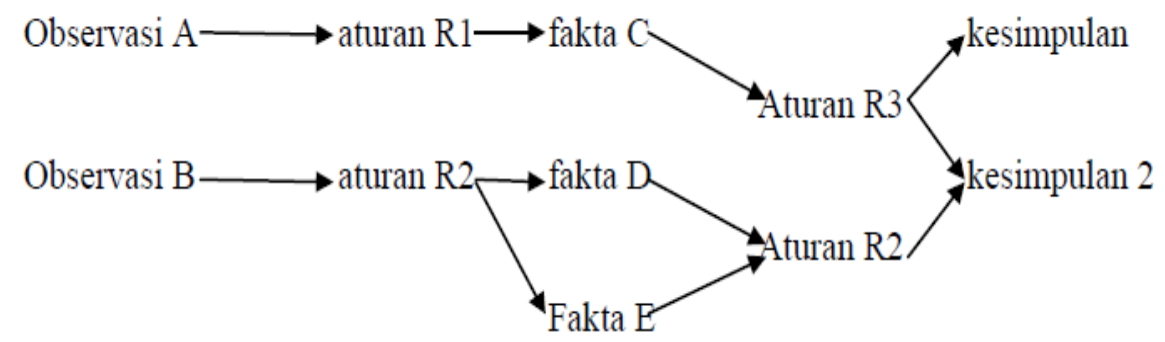

Gambar.1. Proses Forward Chaining

\section{Air Conditioner (AC)}

AC alias Air Conditioner alias Pengkondision Udara merupakan seperangkat alat yang mampu mengkondisikan ruangan yang kita inginkan, terutama mengkondisikan ruangan menjadi lebih rendah suhunya dibanding suhu lingkungan sekitarnya [Astro, 2016]. 


\section{Android}

Menurut Safaat dalam [Vadlya Maarif, Andrian Eko Widodo, 2017] Android adalah "sebuah system operasi untuk perangkat mobile berbasis linux yang mencakup system operasi, middleware dan aplikasi".Android menyediakan platform yang terbuka bagi para pengembang untuk menciptakan aplikasi mereka.

\section{Eclipse}

Fungsi Eclipse utamanya adalah untuk mengembangkan aplikasi java, tetapi juga dapat digunakan untuk mengembangkan aplikasi dalam bahasa pemrograman lain dengan menggunakan plugin, termasuk $\mathrm{C}, \mathrm{C}++$, Cobol, Python, Ruby dan lain-lain. Selain itu, Eclipse juga digunakan untuk mengembangkan aplikasi android.[Sagita, 2015]

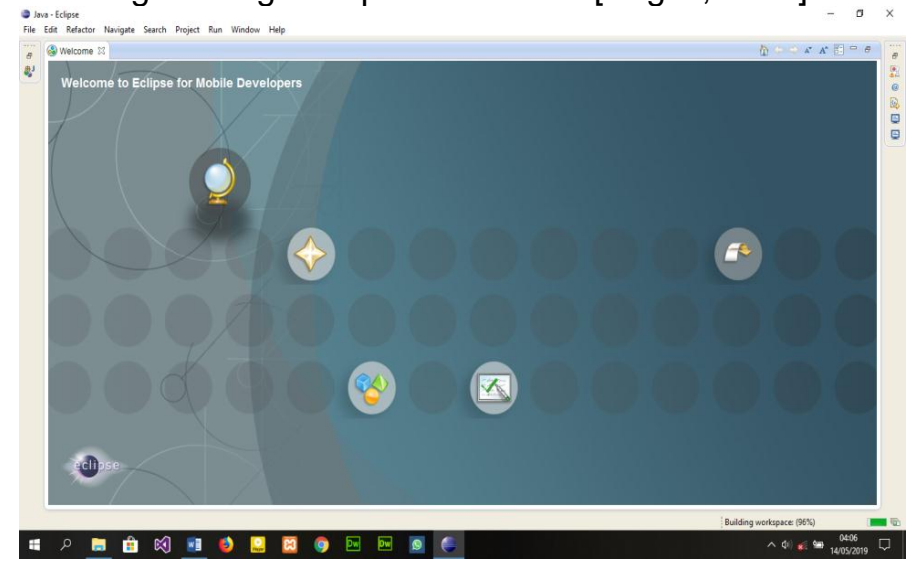

Gambar.2. Tampilan Eclipse

\section{HIPO (Hierarchy Input Proses Output)}

Menurut Al Fatta dalam [Pakpahan, R., Fitriani, Y., 2018], "HIPO merupakan teknik untuk mendokumentasikan pengembangan suatu sistem yang mempunyai tujuan utama".

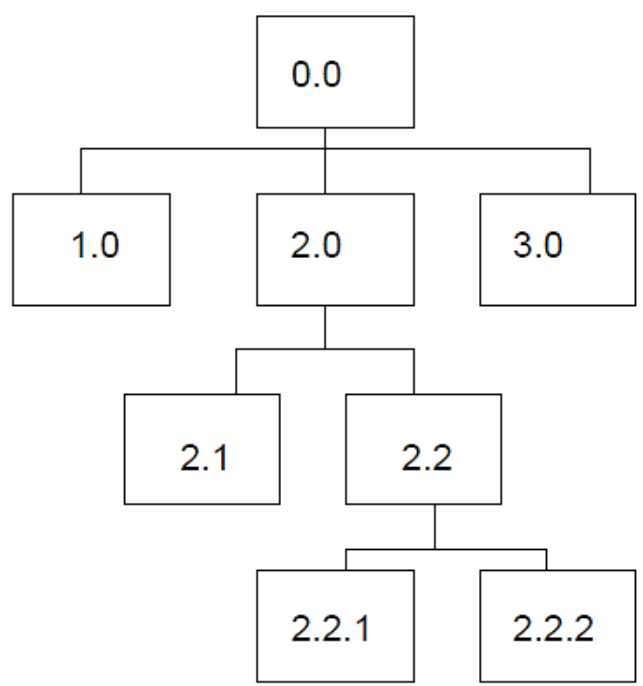

Gambar.3. Hippo 


\section{Flowchart}

Menururt Nuraini [Nuraini, 2015] "Flowchart dapat diartikan sebagai suatu alat atau sarana yang menunjukkan langkah-langkah yang harus dilaksanakan dalam menyelesaikan suatu permasalahan untuk komputasi dengan cara mengekspresikannya ke dalam serangkaian simbol-simbol grafis khusus".

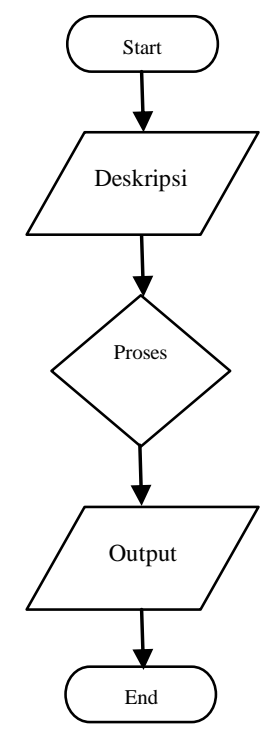

Gambar.4. Contoh Flowchart

\section{METODE PENELITIAN}

Untuk membangun sistem pakar berbasis android yang dapat membantu dalam mendeteksi kerusakan pada pendingin udara (AC) maka diperlukan beberapa metode penelitian antara lain:

1. Metode Wawancara

Merupakan teknik wawancara untuk mengumpulkan data yang mendukung penelitian. Pada penelitian ini, wawancara dilakukan kepada Bapak Faozi Muslim selaku teknisi service AC pada CV. Banyu Mili Teknik.

2. Studi Pustaka

Studi pustaka dilakukan dengan mengumpulkan data-data baik dari buku-buku bacaan, jurnal, paper, maupun artikel-artikel yang berkaitan dengan Air Conditioner (AC), dan sistem pakar dengan metode Forward Chaining.

\section{HASIL DAN PEMBAHASAN}

Pembuatan aplikasi sistem pakar menggunakan data yang bersumber dari pakar, buku, dan internet. Data tersebut digunakan untuk mengetahui berbagai jenis kerusakan AC, gejala dan penanganannya.

Tabel 1. Data Kerusakan AC dan Penanganan

\begin{tabular}{|c|c|}
\hline $\begin{array}{c}\text { Data } \\
\text { Kerusakan AC }\end{array}$ & Penanganan \\
\hline $\begin{array}{l}\text { K01. } \\
\text { Kompresor } \\
\text { rusak }\end{array}$ & $\begin{array}{l}\text { Ganti kompresor dengan } \\
\text { yang baru }\end{array}$ \\
\hline
\end{tabular}

ejournal.bsi.ac.id/ejurnal/index.php/ijse

Copyright @ Universitas Bina Sarana Informatika 


\begin{tabular}{|c|c|}
\hline $\begin{array}{l}\text { K02. Motor } \\
\text { blower rusak }\end{array}$ & $\begin{array}{l}\text { Ganti motor blower dengan } \\
\text { yang baru }\end{array}$ \\
\hline $\begin{array}{l}\text { K03. Bearing } \\
\text { kipas outdoor } \\
\text { rusak }\end{array}$ & $\begin{array}{l}\text { 1. } \begin{array}{l}\text { Bersihkan bearing } \\
\text { menggunakan pelumas } \\
\text { khusus }\end{array} \\
\text { 2. Jika rusak, ganti } \\
\begin{array}{l}\text { bearing dengan yang } \\
\text { baru }\end{array}\end{array}$ \\
\hline $\begin{array}{l}\text { K04. Sirip-sirip } \\
\text { evaporator } \\
\text { kotor }\end{array}$ & $\begin{array}{l}\text { Membersihkan sirip-sirip } \\
\text { evaporator menggunakan } \\
\text { air yang dicampur dengan } \\
\text { cairan pembersih khusus, } \\
\text { semprotkan menggunakan } \\
\text { pompa steam }\end{array}$ \\
\hline $\begin{array}{l}\text { K05. Sirip-sirip } \\
\text { kondensor } \\
\text { kotor }\end{array}$ & $\begin{array}{l}\text { Membersihkan sirip-sirip } \\
\text { kondensor menggunakan } \\
\text { air yang dicampur dengan } \\
\text { cairan pembersih khusus, } \\
\text { semprotkan menggunakan } \\
\text { pompa steam }\end{array}$ \\
\hline $\begin{array}{l}\text { K06. Kapasitor } \\
\text { kompresor } \\
\text { rusak }\end{array}$ & $\begin{array}{l}\text { Ganti kapasitor sesuai } \\
\text { ukurannya }\end{array}$ \\
\hline $\begin{array}{l}\text { K07. Kapasitor } \\
\text { kipas outdoor } \\
\text { rusak }\end{array}$ & $\begin{array}{l}\text { Ganti kapasitor kipas } \\
\text { sesuai ukurannya }\end{array}$ \\
\hline $\begin{array}{l}\text { K08. Spark } \\
\text { pada terminal } \\
\text { utama atau } \\
\text { konektor } \\
\text { kompresor }\end{array}$ & $\begin{array}{l}\text { 1. Mengganti konektor dan } \\
\text { kabel yang terbakar } \\
\text { 2. Kencangkan } \\
\text { sambungan terminal } \\
\text { dan konektor } \\
\text { 3. Periksa kekuatan setiap } \\
\text { sambungan } \\
\end{array}$ \\
\hline $\begin{array}{l}\text { K09. } \\
\text { Kebocoran } \\
\text { refrigerant } \\
\text { pada } \\
\text { sambungan } \\
\text { pipa }\end{array}$ & 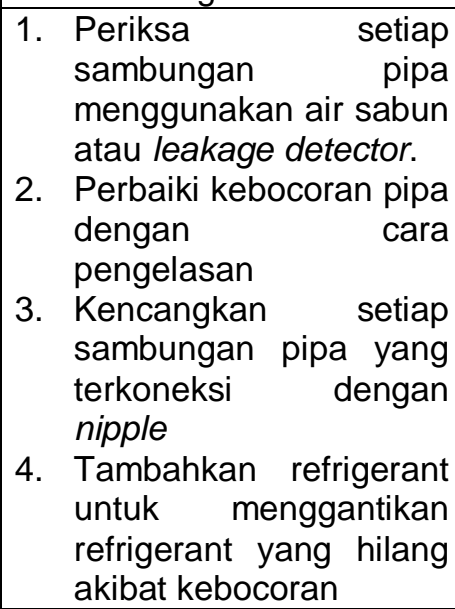 \\
\hline $\begin{array}{l}\text { K10. } P C B \\
\text { kontrol error }\end{array}$ & $\begin{array}{l}\text { 1. Membersihkan PCB } \\
\text { kontrol menggunakan } \\
\text { contact cleaner } \\
\text { 2. Reset aliran listrik } \\
\text { utama pada MCB } \\
\text { dengan cara mematikan } \\
\text { aliran listrik, lalu sekitar } \\
2-3 \text { menit kemudian, } \\
\text { nyalakan kembali. }\end{array}$ \\
\hline
\end{tabular}


Tabel 2. Gejala Kerusakan AC

\begin{tabular}{|l|}
\hline \multicolumn{1}{|c|}{ Gejala Kerusakan AC } \\
\hline G01. AC mati total \\
\hline G02. MCB trip \\
\hline $\begin{array}{l}\text { G03. Suara kompresor berdengung dan } \\
\text { bergetar keras sebelum AC mati total }\end{array}$ \\
\hline $\begin{array}{l}\text { G04. Tidak ada hembusan udara yang } \\
\text { keluar dari blower } \text { AC }\end{array}$ \\
\hline G05. Blower tidak bekerja sama sekali \\
\hline G06. Lilitan motor blower putus \\
\hline G07. Ruangan AC tidak dingin \\
\hline G08. Suara kipas outdoor berisik \\
\hline G09. Putaran kipas outdoor tidak lancar \\
\hline G10. Ruangan AC kurang dingin \\
\hline $\begin{array}{l}\text { G11. Hembusan blower terhambat dan } \\
\text { tidak merata }\end{array}$ \\
\hline G12. Sirip-sirip Evaporator tersumbat \\
\hline G13. Coil kondensor terasa sangat panas \\
\hline G14. Sirip-sirip kondensor tersumbat \\
\hline G15. Kompresor tidak bekerja \\
\hline $\begin{array}{l}\text { G16. Kapasitor kompresor } \\
\text { gembung/pecah }\end{array}$ \\
\hline $\begin{array}{l}\text { G17. Putaran kipas outdoor lemah/kipas } \\
\text { tidak bekerja sama s }\end{array}$ \\
\hline $\begin{array}{l}\text { G18. Terdapat pembekuan pada pipa kecil } \\
\text { (discharge pressure })\end{array}$ \\
\hline G19. LED indikator unit indoor berkedip-ked \\
\hline
\end{tabular}

Tabel 3. Data Diagnosa

\begin{tabular}{|l|}
\hline Data Diagnosa Kerusakan AC \\
\hline K01 : G01, G02, G03 \\
K02 : G04, G05, G06 \\
K03 : G07, G08, G09 \\
K04 : G10, G11, G12 \\
K05 : G13, G14, G15 \\
\hline
\end{tabular}




K06: G07, G15, G16
K07 : G07, G17
K08 : G01, G02
K09: G07, G18
K10 : G01, G19

Tabel 4. Rule Kerusakan

\begin{tabular}{|c|l|}
\hline $\begin{array}{c}\text { Kode } \\
\text { Rule }\end{array}$ & \multicolumn{1}{|c|}{ Rule } \\
\hline K01 & $\begin{array}{l}\text { IF G01 AND G02 AND G03 } \\
\text { THEN K01 }\end{array}$ \\
\hline K02 & $\begin{array}{l}\text { IF G04 AND G05 AND G06 } \\
\text { THEN K02 }\end{array}$ \\
\hline K03 & $\begin{array}{l}\text { IF G07 AND G08 AND G09 } \\
\text { THEN K03 }\end{array}$ \\
\hline K04 & $\begin{array}{l}\text { IF G10 AND G11 AND G12 } \\
\text { THEN K04 }\end{array}$ \\
\hline K05 & $\begin{array}{l}\text { IF G13 AND G14 AND G15 } \\
\text { THEN K05 }\end{array}$ \\
\hline K07 & $\begin{array}{l}\text { IF G07 AND G15 AND G16 } \\
\text { THEN K06 }\end{array}$ \\
\hline IF G07 AND G17 THEN K07 \\
\hline K09 & IF G07 AND G18 THEN K09 \\
\hline
\end{tabular}

1. Penggambaran HIPO (Heirrachy Input Proccess Output) yang akan diterapkan pada aplikasi.

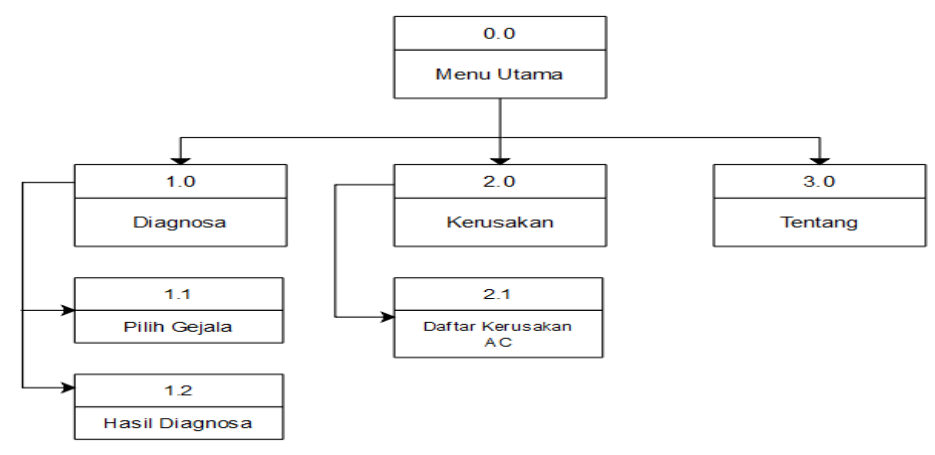

Gambar 5. HIPO Sistem Pakar Kerusakan AC 
2. Flowchart sistem yang akan diterapkan pada aplikasi sistem pakar deteksi kerusakan AC.

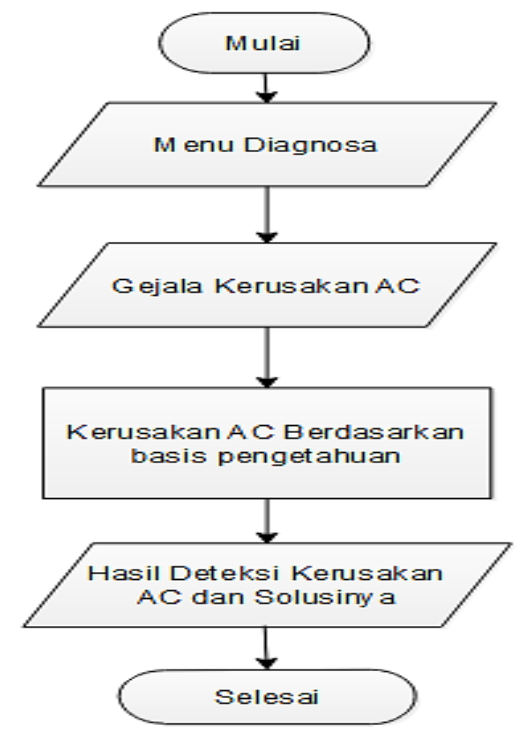

Gambar 6. Flowchart Diagnosa Kerusakan AC

3. Implementasi

Setelah semua proses selesai dikerjakan, langkah berikutnya adalah mengimplementasikan aplikasi yang akan dibuat ke perangkat android. Berikut ini adalah tampilan yang diimplementasi.

A. SplashScreen

Pada halaman SplashScreen menampilkan gambar aplikasi

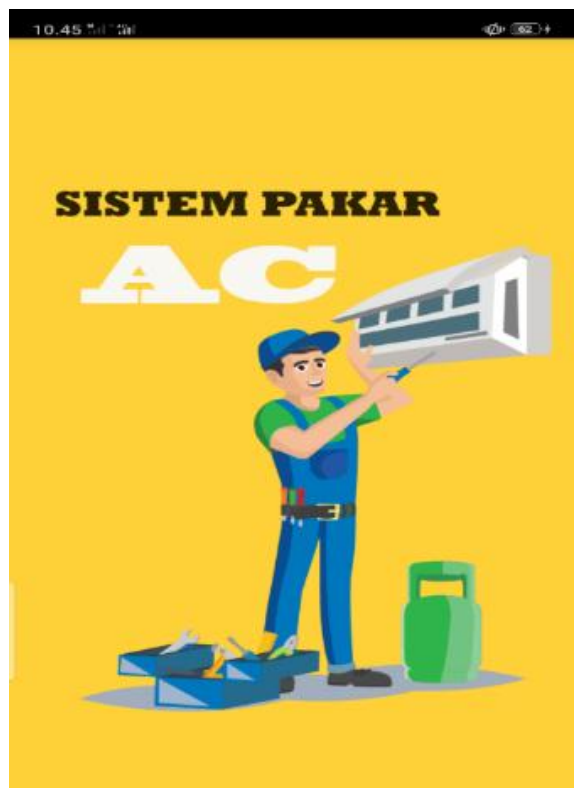

Gambar 7. Halaman Splashscreen 
B. Menu Utama

Pada halaman menu utama menampilkan 4 menu, yaitu menu Diagnosa, menu Info, menu Tentang dan menu Keluar. Pengguna dapat memilih masingmasing menu yang akan dituju.

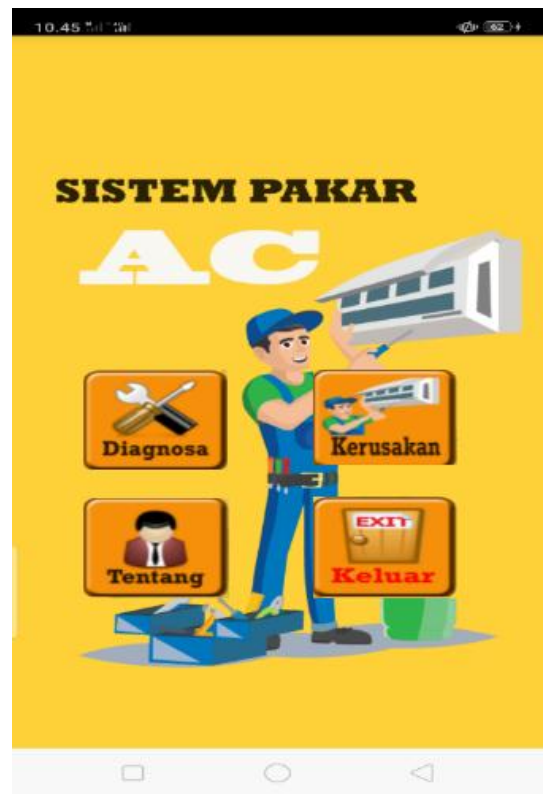

Gambar 8. Halaman Menu Utama

\section{Diagnosa}

Pada halaman Diagnosa menampilkan pilihan daftar gejala kerusakan AC. Setelah memilih gejala kerusakan AC yang sesuai, kemudian klik tombol Hasil Diagnosa untuk menampilkan hasil diagnosa kerusakan AC.

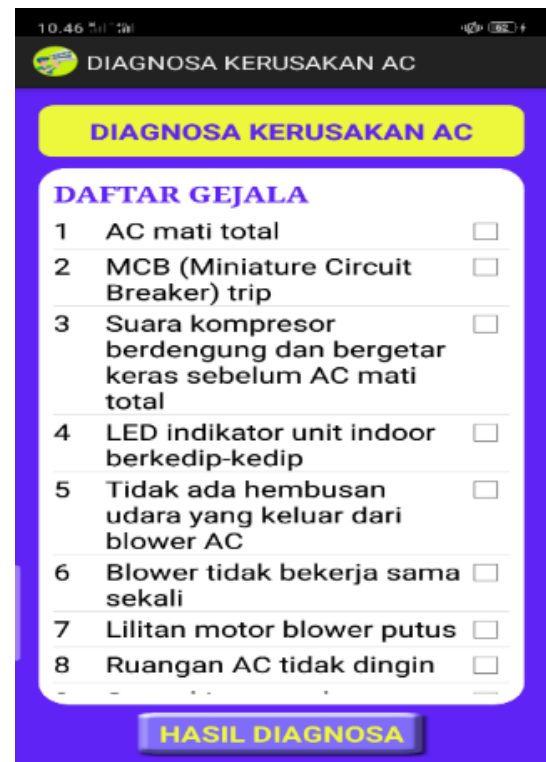

Gambar 9. Halaman diagnosa 
D. Hasil Diagnosa

Pada halaman Hasil Diagnosa menampilkan hasil kesimpulan kerusakan AC berdasarkan gejala kerusakan AC yang dipilih, Hasil kesimpulan tersebut menampilkan kerusakan AC, gejala dan solusi penanganannya. Kemudian klik tombol Menu Utama untuk kembali ke

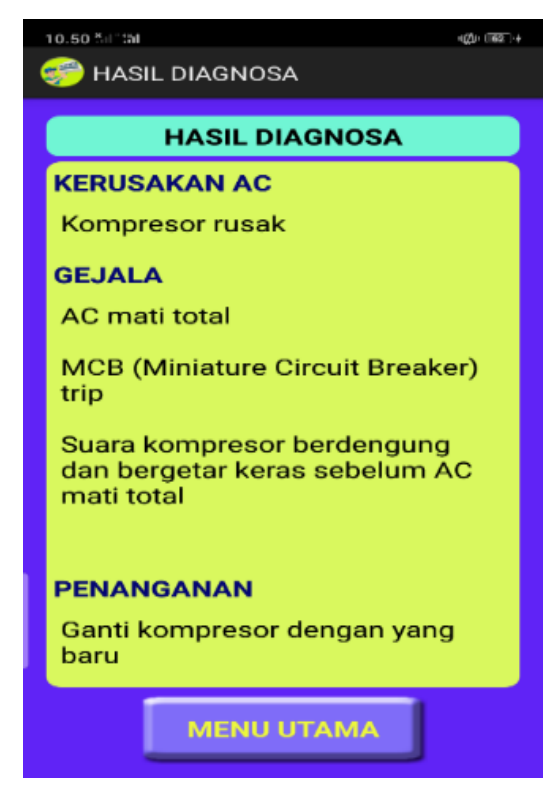

Gambar 10. Halaman Hasil Diagnosa

E. Kerusakan

Pada halaman Kerusakan menampilkan daftar kerusakan AC. Dengan mengklik kerusakan AC maka akan ditampilkan Info rincian kerusakan AC.

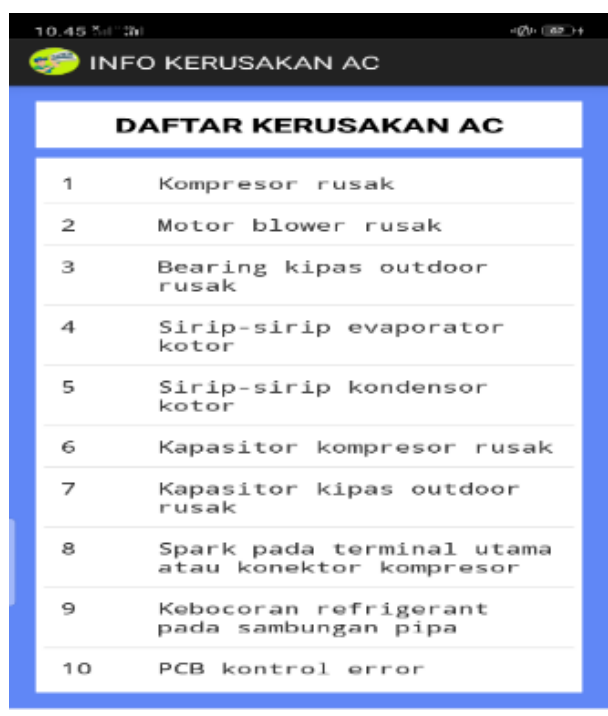

Gambar 11. Halaman Info Kerusakan AC 


\section{E. KESIMPULAN}

Berdasarkan pembahasan yang telah dilakukan pada aplikasi sistem pakar untuk mendeteksi kerusakan $\mathrm{AC}$, penulis dapat mengambil kesimpulan yaitu:

1. Pada aplikasi sistem pakar kerusakan AC berbasis android digunakan untuk mendeteksi kerusakan pada AC (Air Conditioner) berdasarkan penyebabnya dan memberikan solusi penanganannya.

2. Metode yang digunakan dalam mendeteksi kerusakan AC dalam aplikasi tersebut adalah Forward Chaining.

3. Hasil perancangan berupa tampilan yang berisi data tentang kerusakan $\mathrm{AC}$, gejala-gejala kerusakan, solusi dan hasil deteksi kerusakan AC berdasarkan gejala.

\section{REFERENSI}

Astro, T. 2016. Cara Kerja Sistem AC Ruangan. Diambil dari https:// cvastro.com/cara-kerja-sistem-ac-ruangan.htm

Ma'rifati IS, Kesuma C. 2018. Pengembangan Sistem Pakar Mendeteksi Penyakit Pencernaan. J. Evolusi 6: 41-48.

Nuraini R. 2015. Desain Algorithma Operasi Perkalian Matriks Menggunakan Metode Flowchart. J. Tek. Komput. Amik Bsi 1: 146.

Pakpahan, R., Fitriani, Y. \& A. 2018. Sistem Informasi Perancangan Aplikasi Data Record Training Karyawan. Tek. Komput. IV(2): 13-18.

Resmiati R, Supriatna AD. 2016. Pengembangan Sistem Pakar Diagnosis Penyakit Cabai Paprika Berbasis Android. J. Algoritm. 13: 191-197.

Sagita SRIM. 2015. Aplikasi Informasi Negara Asean Pada Smartphone Berbasis Android. Fakt. Exacta 9: 190-199.

Vadlya Maarif, Andrian Eko Widodo DYW. 2017. Aplikasi Tes IQ Berbasis Android.

Yuwono DT, Fadlil A, Sunardi. 2017. Penerapan Metode Forward Chaining Dan Certainty Factor Pada Sistem Pakar. Klik 04: 136-145. 